DOI: $10.14451 / 1.183 .38$

\title{
АНАЛИЗ СОСТОЯНИЯ МИРОВОГО РЫНКА ПШЕНИЦЫ И ПЕРСПЕКТИВЫ РОССИИ ПО РАСШИРЕНИЮ ЭКСПОРТНОГО ПОТЕНЦИАЛА *
}

\author{
(c) 2020 Жиляков Дмитрий Иванович \\ кандидат экономических наук \\ Курская Государственная сельскохозяйственная академия имени И.И. Иванова, Россия, Курск \\ E-mail: zhilyakov@yandex.ru \\ (c) 2020 Башкатова Валентина Яковлевна \\ Курский институт кооперации (филиал) \\ АНО ВО «Белгородский университет кооперации, экономики и права», Россия, Курск
}

(c) 2020 Плахутина Юлия Викторовна

кандидат экономических наук

Курская Государственная сельскохозяйственная академия имени И.И. Иванова, Россия, Курск

E-mail: juliasonina2008@yandex.ru

(c) 2020 Петрушина Ольга Вячеславовна

Курская Государственная сельскохозяйственная академия имени И.И. Иванова, Россия, Курск

E-mail:petao@yandex.ru

(c) 2020 Зюкин Данил Алексеевич

кандидат экономических наук

Курская Государственная сельскохозяйственная академия имени И.И. Иванова, Россия, Курск

E-mail: nightingale46@rambler.ru

В статье анализируется ситуация на мировом рынке зерна, выделяется анализ на мировом рынке пшеницы, рассматривается место России как одного из крупнейших экспортеров зерновых в структуре мирового экспорта пшеницы, анализируется динамика российского зернового экспорта. Было выяснено, что в сезоне 2019/20 гг. прогнозируется рост производства и потребления зерна на мировом рынке. Также в ходе исследования было установлено, что роль России в качестве мирового экспортера зерновых год от года укрепляется.

Ключевые слова: зерновое хозяйство, пшеница, экспорт зерна, мировой рынок пшеницы.

Зерновые культуры составляют основу рациона людей во многих странах мира. В зависимости от климатических особенностей и культурных традиций, наиболее востребованными на рынках различных стран являются разные виды зерновых культур. Поэтому возможность обеспечения эффективного экспорта зерна позволяет добиться не только получения валютной выручки, но и улучшения торговых и политических отношений со страной-партнером.

Россия обладает высоким экспортным потенциалом, что в последние годы часто ставит ее в число лидеров по объемам экспорта зерна на мировом рынке, а объемы экспорта зерновых культур из России вполне сопоставимы с отечественным экспортом вооружений [1]. Однако позиции России как экспортера зерна укрепились сравнительно недавно, а крупнейшими экспортерами на мировом зерновом рынке долгое время были пять игроков: США, Канада, Евросоюз, Аргентина и Австралия, которые в совокупности покрывали более 85\% мирового рынка своим экспортом [2]. В советское время наша страна была нетто-импортером, однако в переходный период собственное животноводство было разрушено, что существенно сократило внутренний спрос. В дальнейшем увеличение валовых сборов позволило сформировать высокий экспортный потенциал и к 2018 г. доля России и Украины достигла более $10 \%$, а Россия стала крупнейшим экспортером пшеницы [3]. На данный момент в России активно развивается животноводство, опираясь на качественное кормовую базу, где важнейшее место занимает именно зерновая

* Статья подготовлена при финансовой поддержке РФФИ в рамках научного проекта № 18-310-00211 
отрасль [4]. Этот фактор активизировал рост внутреннего спроса на зерно, но вместе с этим именно экспорт является инструментом стимулирования валовых сборов, так как за счет него осуществляется санирование внутреннего рынка, а агропроизводители сформировали крупное доходное направление поступления валютной выручки [5].

Однако следует учесть, что, во-первых, приоритетом государственной аграрной политики России должно являться обеспечение продовольственной безопасности ее населения, и только потом решаться вопросы расширения экспорта зерна [6]. Тем не менее, при рациональном использовании зерновых ресурсов и формировании механизма регулирования зернового баланса Россия способна достичь как полного удовлетворения внутренних потребностей в зерне, так и увеличить свои экспортные возможности. Поэтому реализация уже имеющегося высокого экспортного потенциала вполне может осуществляться без негативного влияния на процессы импортозамещения [7].

На мировом рынке зерна по прогнозным данным в 2019/20 гг. ожидается небольшое сокращение объемов производства зерна относительно сезона 2015/16 гг. (-5,1\%), но небольшой прирост к предыдущему периоду (2,3\%) [8]. Ожидается рост объемов потребления, что, соответственно, вызовет рост предложения и объемов торговли. Относительно базисного периода ожидается рост запасов на $8 \%$, однако относительно периода 2017/18 гг. запасы снизятся на $0,6 \%$ (рисунок 1 ).

Наиболее крупным из торгуемых видов зерна на мировом рынке и основой российского экспорта является пшеница. Производство пшеницы делится по так называемым поясам в разрезе полушарий планеты. Пшеничный пояс северного полушария включают в себя Россию, страны Восточной и Западной Европы, Украину, в азиатской части Казахстан, Китай, Индию и Пакистан, Иран на Ближнем Востоке, на североамериканском континенте США, Канаду. В южном полушарии пшеницу производят Австралия и Аргентина. Австралия, обеспечивающая пшеницей страны Азии, Африки и Ближнего Востока, экспортирует не так много в сравнении с ведущими экспортерами, но, тем не менее, ее зерно оказывает сильное влияние на мировые цены.

На мировом рынке пшеницы прослеживается динамический рост всех показателей, и ожидается, что больше остальных вырастет предложение из-за достижения нового рекордного уровня, превысившего показатели предыдущего сезона. Мировое производство пшеницы в динамике увеличится на 4,2\%, предложение возрастет на $7,1 \%$, рост потребления составит $5,9 \%$, а торговли $-3,9 \%$. Относительно предыдущего периода 2017/18 гг. рост потребления и предло-

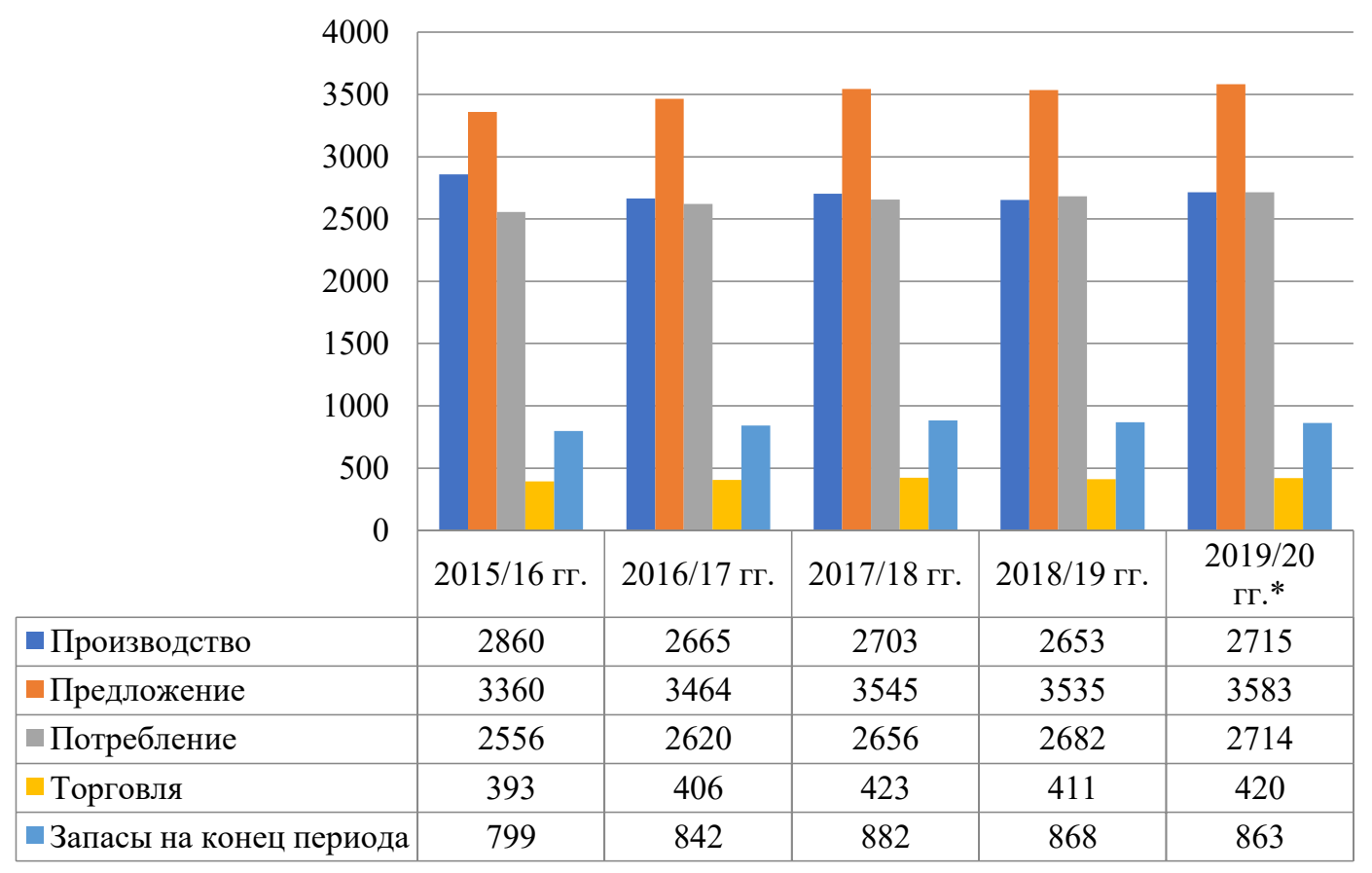

Рисунок 1. Баланс зерна на мировом рынке, млн. т. 
жения составит $1,5 \%$ и $1,8 \%$ соответственно (рисунок 2).

В 2018 г. общий объем мирового экспорта пшеницы превысил 190 млн. т., при этом доля России на рынке мирового экспорта пшеницы за период 2016-2018 гг. значительно возросла с $13,3 \%$ до 23,3\% [9], что ставит Россию на лидирующую позицию в мировом экспорте пшеницы. Канада и США в структуре экспорта пшеницы по странам мира в процентном соотношении зани- мают вдвое меньшую долю, чем Россия. В сопоставление с Россией также может идти Франция и Украина. Расхождение с остальными странами по экспорту пшеницы составляет практически 4 раза и более (рисунок 3).

На сезон 2019/20 гг. по данным Продовольственной и сельскохозяйственной организации Объединенных Наций [10] по объемам производства и экспорта пшеницы среди стран, обеспечивающих наиболее крупные объемы экспорта,

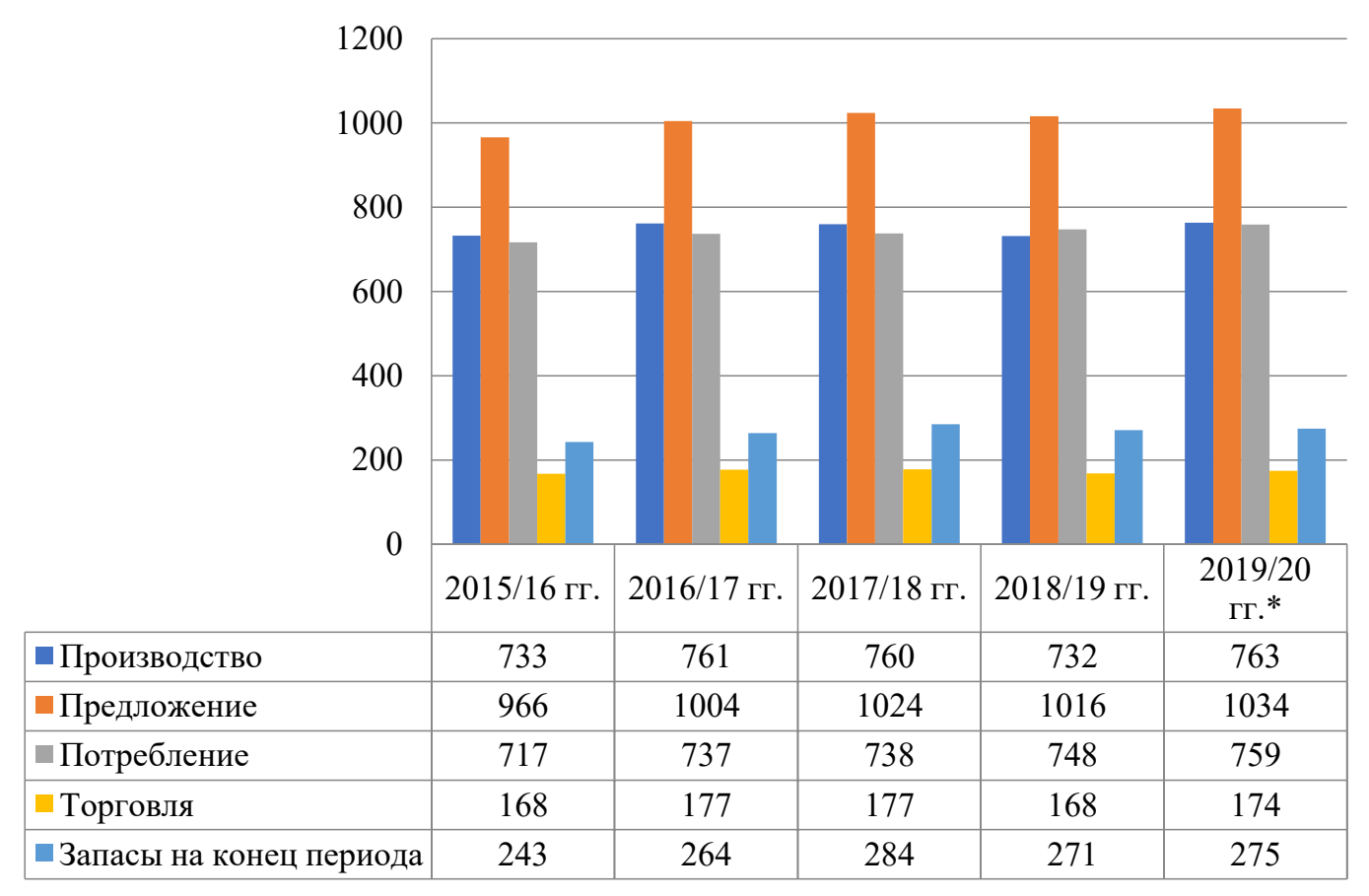

Рисунок 2. Баланс на мировом рынке пшеницы, млн. т.

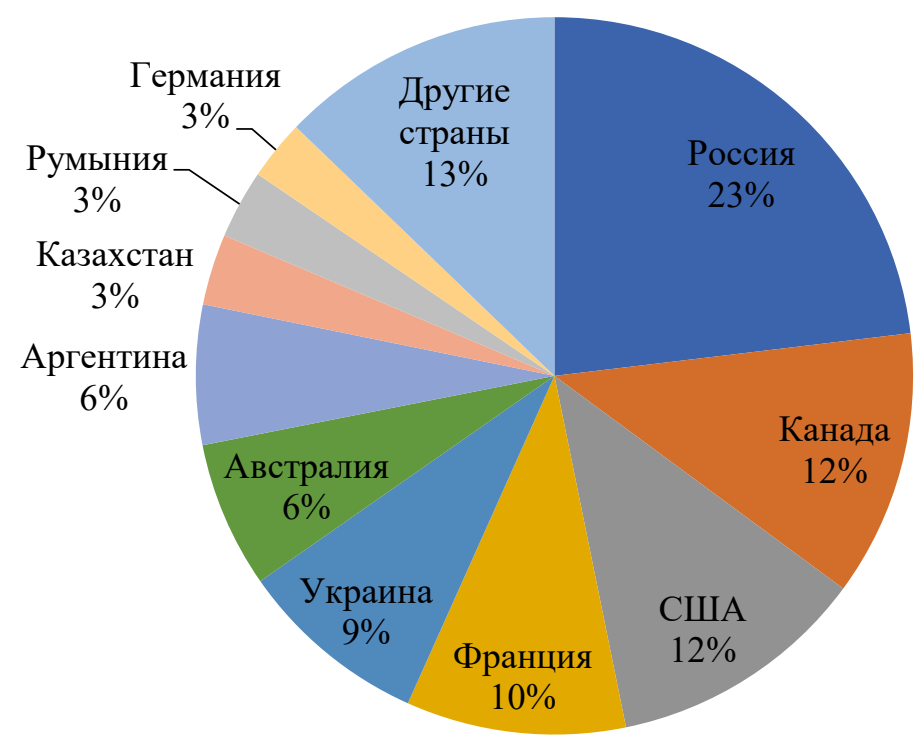

Рисунок 3. Структура экспорта пшеницы по странам мира в 2018 г.,\% 
превалирующее положение по производству будет принадлежать Евросоюзу, а по объемам экспорта - России (рисунок 4).

Объемы производства пшеницы в ЕС вдвое выше, чем России, в 2,9 раза выше, чем у США, и в 4,5 раза выше, чем в Канаде, т.е. среди стран, составляющих тройку лидеров по объемам экспорта пшеницы.

Рассматривая соотношение производства и экспорта, наглядно видно, что в странах, где объемы производства ниже, чем в ЕС и России, экспорт пшеницы занимает больше от объема производства (рисунок 5).

Наименьшую долю по отношению к производству экспорт зерна имеет в странах Евросою- 3а. На второй позиции Россия, также меньше 50\% от производства экспортирует США. Ближайший конкурент России на Европейском континенте Украина экспортирует $65,5 \%$ от производства. Почти 3/4 от производства пшеницы экспортирует Канада, немногим меньше - Аргентина, т.е. эти страны на внутренне потребление оставляют гораздо меньше, чем страны, где объемы производства в разы выше.

Мировые цены на пшеницу до 2014 г. были на порядок выше, чем с наступлением более урожайных периодов. Рекордно низкий уровень цен на пшеницу был зафиксирован в 2016 г., когда относительно предыдущих периодов значительно выросло предложение культуры на миро-

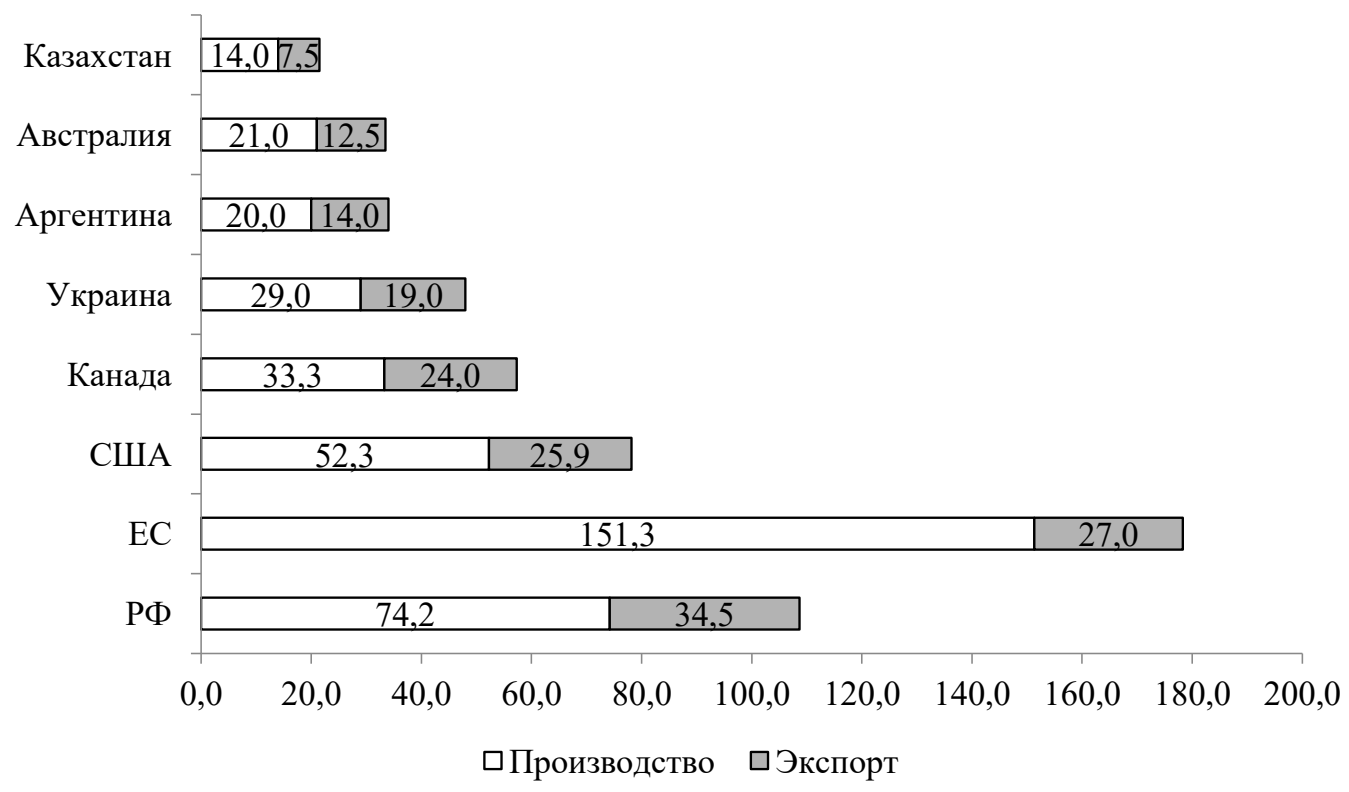

Рисунок 4. Прогноз объемов производства и экспорта пшеницы среди крупнейших экспортеров мира в сезоне 2019/20, млн. т.

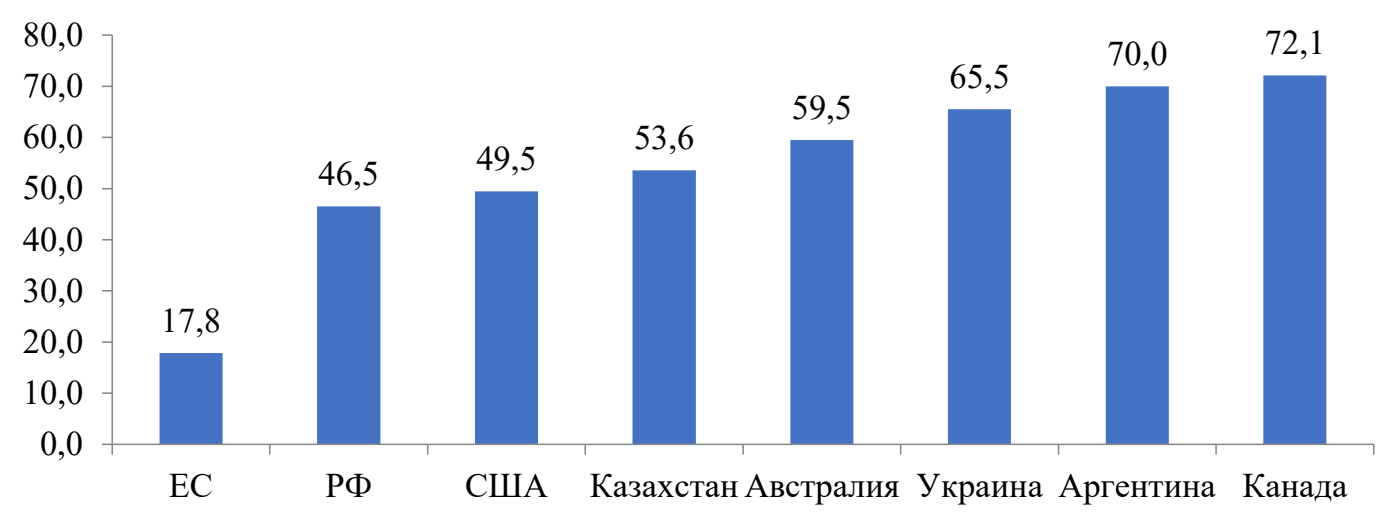

Рисунок 5. Доля экспорта от объемов производства пшеницы среди крупнейших мировых экспортеров по прогнозу в 2019/20 гг.,\% 
вом рынке (рисунок 6).

В сезоне 2018/19 гг. наблюдается наибольший уровень цен на пшеницу за период 2015-2019 гг., что связано со снижением уровня предложения и потребления на мировом рынке пшеницы. На фоне высоких урожаев зерна в России благоприятная ценовая конъюнктура на мировом рынке способствовала динамичному росту объемов российского экспорта пшеницы - за десятилетие экспорт пшеницы увеличился в 2,6 раза, достигнув почти 44 млн. т в 2018 году. Ослабление рубля также способствовало укреплению позиций российских экспортеров на зарубежных рынках, например, потеснив Францию с египет- ского рынка, который для России является самым крупным (рисунок 7).

Рекорд валового сбора зерна 2017 года показывает, что последний урожай не является пределом даже при текущих факторах возделывания зерновых. При этом ресурсы повышения урожая зерновых в России еще далеки от исчерпания, в первую очередь, за счет повышения урожайности. Учитывая ограничения внутреннего спроса на зерно, в структуре производства преимущество будет отдаваться пшенице, как основному экспортоориентрованному виду зерновых. Поэтому в перспективе наращивание присутствия на мировом рынке российской пшеницы явля-

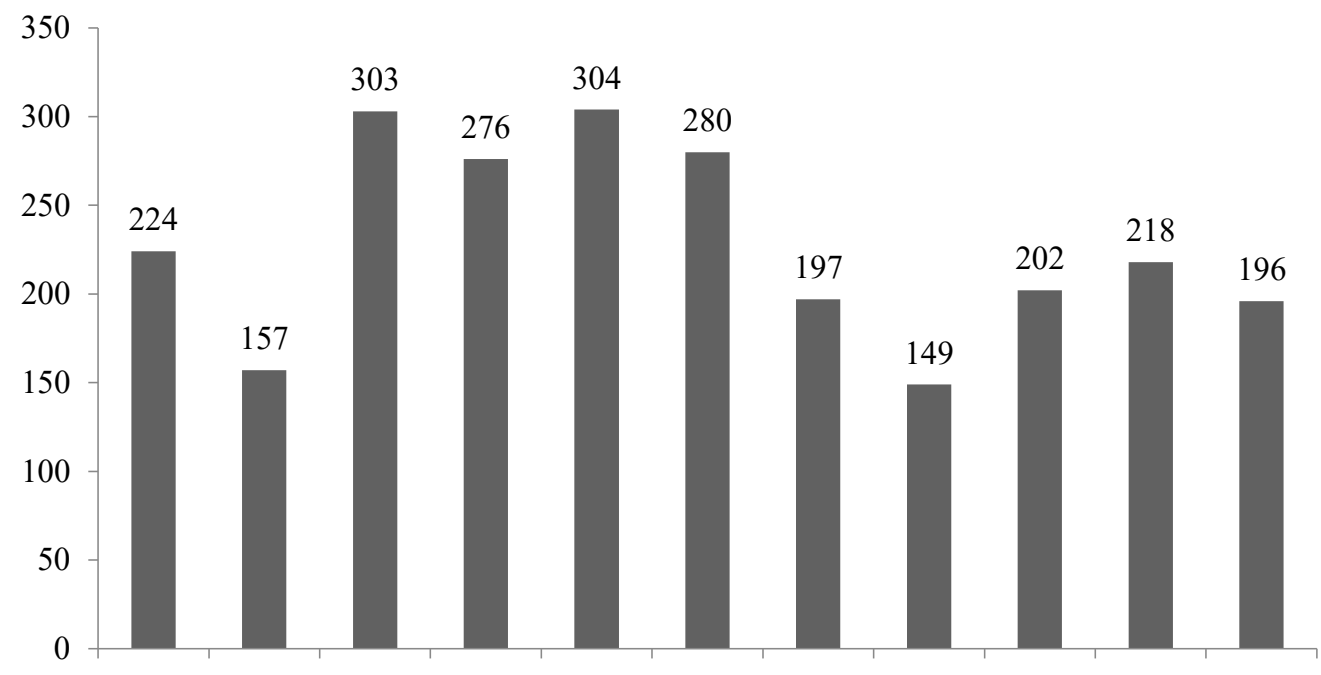

2009 г. 2010 г. 2011 г. 2012 г. 2013 г. 2014 г. 2015 г. 2016 г. 2017 г. 2018 г. 2019 г.

Рисунок 6. Динамика мировых цен на пшеницу, долл. США за тонну

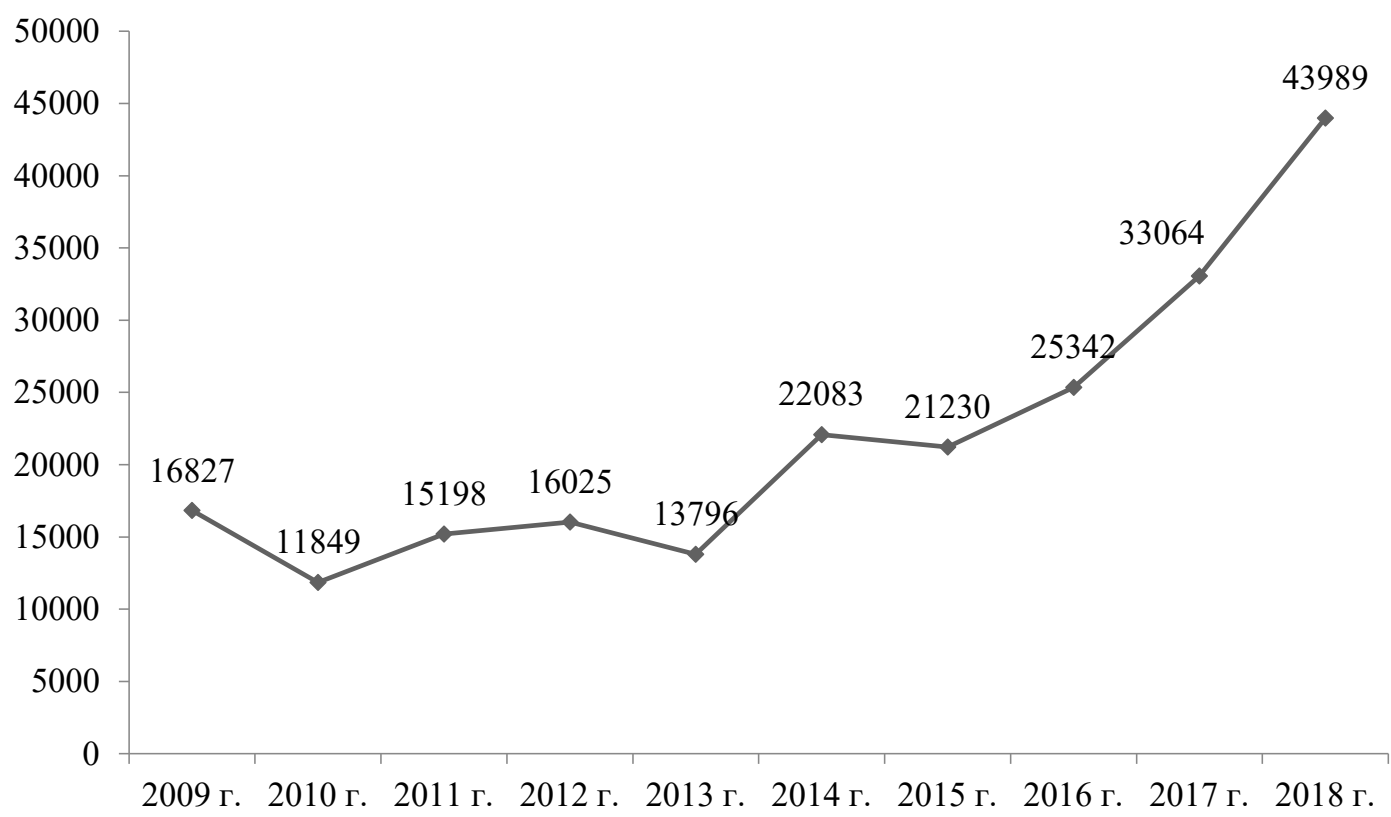

Рисунок 7. Динамика российского экспорта пшеницы в 2009-2018 гг., тыс. т. 
ется способом не только обеспечить валютное поступления в отрасль, но и стимулом к дальнейшему наращивания урожаев за счет интенсивных и инновационных факторов. В современных условиях залогом расширения экспорта является внешнеэкономическое сотрудничество политических элит стран, поэтому продвижения не только пшеницы, но и других видов продовольствия на экспорт следует сопровождать ад- министративной и маркетинговой поддержкой государства. Обоснованность такого внимания со стороны государства определяется многими факторами, в том числе и тем, что на фоне введения ограничительных мер на российский экспорт продукции ВПК, нестабильности цен на энергоресурсы пшеницу следует рассматривать как один из наиболее стабильных источников поступления валютной выручки в страну.

\section{Библиографический список}

1. Давтян М.А., Воробьев Д.Ю. Конкурентоспособность России на мировом рынке зерна // Труд и социальные отношения. 2019. № 5. С. 70-83.

2. Федорова В.И., Кузьменко С.С. Позиции Российской Федерации на мировом рынке зерна // Вестник Московского университета им. С.Ю. Витте. Серия 1: Экономика и управление. 2018. № 3 (26). С. 16-21.

3. Development of the grain market export potential / Tyupakov K.E., Reznichenko D.S., Klochko E.N., Verty M.V., Cherner N.V.// International Journal of Recent Technology and Engineering. 2019. T. 8. № 3. C. 7146-7152.

4. Чистяков Г.В., Жиляков Д.И. Анализ отрасли свиноводства в рамках реализации государственных программ развития // Вестник Курской государственной сельскохозяйственной академии. 2017. № 5. С. $73-77$.

5. Зюкин Д.А. Развитие экспортного потенциала зернового хозяйства России // Экономика сельскохозяйственных и перерабатывающих предприятий. 2019. № 1. С. 58-61.

6. Алтухов А.И. Достижение продовольственной независимости страны на основе новой государственной аграрной политики // Региональный вестник. 2016. № 2 (3). С. 2-5.

7. Зюкин Д.А. Формирование стратегии развития зернопродуктового подкомплекса АПК как необходимого элемента успешной реализации политики импортозамещения продовольствия // Региональный вестник. 2018. № 6 (15). С. 31-33.

8. Публикуемая ФАО сводка предложения зерновых и спроса на зерновые. Продовольственной и сельскохозяйственной организации Объединенных Наций. [Электронный ресурс]. Режим доступа: http://www.fao. org/worldfoodsituation/csdb/ru/ (Дата обращения: 24.02.2020 г.).

9. Об экспорте пшеницы из России в 2015-2019 гг. Экспертно-аналитического центра агробизнеса АБ-центр. [Электронный ресурс]. Режим доступа: https://ab-centre.ru/news/ob-eksporte-pshenicy-iz-rossii-v-20182019-gg (Дата обращения: 24.02.2020 г.).

10. Экспортные рекорды зерна. Ambarexport. [Электронный ресурс]. Режим доступа: https://ambarexport.ua/ru/ blog/export-records-of-grain (Дата обращения: 24.02.2020 г.). 